\title{
Investidas invertidas: performance e política na obra de Kent Monkman/Mischief
}

\author{
Leonardo Carvalho Bertolossi
}

resumo Entre 2007 e 2008, esteve em exibição no National Museum of the American Indian, a exposição "Remix: New Modernities in a Post-Indian World”, composta por 15 artistas indígenas mestiços, que através de seus trabalhos problematizaram as fronteiras da autenticidade, da criatividade das indianidades contemporâneas, e do sentido de afirmar-se indígena hoje. Black Indians, Gay Native, dilemas da cibercultura, dentre outras imagens estiveram presentes nas remixagens "pós-indígenas”, que experimentaram novas acepçóes sobre corpo, gênero, etnicidade, territorialidade e transitorialidade. O objetivo deste artigo é refletir sobre a produção de Kent Monkman, gay, ascendência cree, desde esta exposição até a atualidade. Através da personagem drag-queen half-breed Miss Chief, inspirada na cantora Cher, e constituída em suas pinturas, fotografias e vídeo-arte, Monkman tem realizado performances reinventando a romântica imagística oitocentista que inscreve os "noble savage" em sublimes paisagens, questionando estereótipos da sexualidade na conquista européia e explorando relaçôes com xenofobia e imperialismo. Criticado como "erótica do genocídio", o "trickster" afirma que objetiva inverter poderes e papéis sexuais indígenas tradicionais à ampliação da reflexão sobre o "third gender" nos mundos indígenas norte-americanos. Evocando os "two-spirited", criticando a mitologia do ultra-macho indígena ao destacar as "perversôes" entre índios e brancos, Monkman pergunta-se: quem "desloca" quem?

palavras-chave Indianidade. Sexualidade. Performance.

\begin{abstract}
"Americans are in a comfort zone with their personal beliefs about who they are, and I think this goes back to the origins and the evolution of their mythology. That's what I am touching on my paintings - that there are flaws in this mythology that they are still hanging on to." (Furnish, 2006)
\end{abstract}

\section{Introdução}

O objetivo deste artigo é refletir criticamente acerca do trabalho artístico de Kent Monkman e suas implicaçóes para um debate antropológico sobre as interseçôes entre concepções de diferenças sociais constitutivas de marcadores étnico/ raciais, de gênero e sexualidade, assim como seus desdobramentos com ideários de nação decorrentes destas diferenciaçóes.

Pergunta-se como a obra deste artista pode nos ajudar a pensar alternativas criativas que operem na dissolução ou inversão de dilemas do colonialismo, suas fantasias, dispositivos e discursividades. Através da aproximação do objeto escolhido com uma bibliografia antropológica sobre o discurso colonial e suas implicações, se pretende observar as estratégias e habilidades de suas açóes produtoras de estereótipos, ansiedades e violências produtoras de diferenças subjetivas e sociais enquanto desigualdades estereotipadas e arriscadas a serem controladas.

A ideia é observar a produção de Monkman através de sua personagem alter ego drag-queen Mischief apontando os horizontes imaginativos abertos por sua política estética e performática, 
as "diásporas" simbólicas imputadas e manipuladas e a fabricação de uma subjetividade outra que implica na aquisição de direitos e reconhecimento social.

Através de sua produção, poderemos observar sua crítica aos essencialismos de Estado, fabricadores de estereótipos assim como os essencialismos estratégicos desde um lugar vitimizado e subalterno como produtores de novos folclorismos atavizadores violentos e desiguais. Uma reflexão sobre o papel político de uma visualidade que permite deslocar e por em risco as certezas e os controles estatais das identidades sociais, assim como as potências e os perigos dos contágios através de associações imagéticas híbridas também serão contempladas nesta reflexão ${ }^{1}$.

\section{Os horizontes imaginativos de Kent Monkman/Mischief e dos artistas pós-indígenas}

1952, Ontário, Canadá. Robert McMichael, fotógrafo e colecionador de arte, e sua mulher Signe Sorense McMichael, decidiram comprar dez acres de terra no vilarejo de Kleinburg, Ontário. Inspirados pela bucólica paisagística local que lhes evocara a memória de um Canadá selvagem e distante, o casal resolveu construir uma casa para abrigar sua futura coleção de arte, a McMichael Canadian Art Gallery.

Construída num estilo arquitetônico inspirado nos tipis dos índios Ojibwa e Chippewa, de origem Anishinaabe, a casa nomeada "Tapawingo", "lugar de alegria" numa língua nativa Anishinaabe, abrigaria uma vasta coleção que atualmente se constitui de aproximadamente cinco mil e quinhentas obras de arte. Robert McMichael e sua mulher começaram sua coleção adquirindo seis mil obras do pintor Tom Thompson e do chamado Grupo dos Sete, que compóem atualmente o panteão de pintores históricos fundadores da arte canadense. A galeria então se tornaria "o lar espiritual do Grupo dos Sete" na memória nacional ${ }^{2}$.

Agosto de 1994, McMichael Canadian Art Gallery. Rompendo com a calma matinal de mais um dia de visitação habitual, os presentes puderam ouvir um trotar de cavalo invadindo a galeria. De repente, o trote se volveu meio galope, relincho, passo e pausa - Mischief havia chegado. Montada sobre um cavalo branco, a esguia e atlética personagem drag-queen adentrava o recinto portando um imenso cocar com penas brancas e negras, espécie de sutiã indígena, joackstrap, aljava e flechas Louis Vuitton e salto alto.

Inspirada pelo imaginário sobre os índios americanos $^{3}$ presente nos diários oitocentistas dos pintores românticos George Catlin e Paul Kane, Mischief resolve agir. Ao chegar na sala dos fundadores da McMichael Gallery, a personagem obrigou inocentes homens nus a se tornarem seus modelos de pintura, tendo terminado sua sessão performática "Group of Seven Inches", vestindo-os como os exemplos mais autênticos do homem europeu.

Mischief Share Eagle Testickle é a personagem alter-ego de Kent Monkman, artista canadense gay com ascendência irlandesa, inglesa e indígena da tribo Cree. Mischief, sua drag-queen half-breed, é apresentada e performatizada nas principais galerias de arte e museus do Canadá, como a National Gallery of Canada, a The Art Gallery of Ontario e o The Montreal Museum of the Fine Arts. Monkman exibe também sua vasta produção pictórica e performática sob a linguagem conceitual das instalações, performances e pinturas nos Estados Unidos e na Austrália, como no National Museum of the American Indian e na 17th Biennale of Sidney - The Beauty of Distance, para citar alguns exemplos ${ }^{4}$.

Monkman possui ainda uma produção intensa de vídeo-arte em que é roteirista, ator 
e diretor, retratando as performances de sua alter ego Mischief, muitas delas premiadas, como o filme "Shooting Geronimo" (super 8 mm, 11:11), de 2006, ganhador do Best short Drama, 2007 imagineNATIVE Film and Media Arts Festival Toronto. Dentre uma série de congratulaçóes ao longo de sua carreira, o artista recebeu inúmeros prêmios pelo filme " $A$ Nation is Coming”' (beta SP, 24') como: Best Experimental, The Alberta Motion Picture Industry Association, 1997; Best Craft (editing - non dramatic), The Alberta Motion Picture Industry Association, 1997, Best Experimental, The American Indian Film and Video Competition, 1997 e Judges Choice Award, The American Indian Film and Video Competition, 1997.

Mas quem, afinal, é Mischief? E Kent Monkman? Qual a relevância deste artista e produção para uma reflexão antropológica? Qual antropologia ${ }^{5}$ podemos encontrar a partir destas personagens?

Tive a oportunidade de conhecer o trabalho artístico de Kent Monkman no decorrer do meu mestrado em Antropologia Social pelo Museu Nacional-UFRJ, quando desenvolvi uma pesquisa sobre o National Museum of the American Indian, um museu nacional norte-americano inaugurado em 2004 em Washington D.C, sob a tutela do Smithsonian Institute, e com o objetivo de representar os índios de todo o continente americano. Administrado e gerenciado por indígenas norte-americanos ${ }^{6}$, o NMAI possui além de sua direção, membros de conselhos e uma equipe de curadores indígenas que constituíram junto das lideranças tribais representadas as três exposiçôes permanentes da exposição: "Our Universes", "Our Peoples" e "Our Lives".

Estas exposiçôes apresentam um vasto panorama da vida indígena nas Américas desde as tradiçôes de enunciação e ritualização mítica dos mundos indígenas; imagens do contato com o mundo europeu; e dilemas e questóes da identidade e vida cotidiana indígena na contemporaneidade. Além destas exposições, o NMAI apresenta regularmente mostras temporárias com a produção artística recente destas populaçóes, dentre elas, uma parcela significativa é dedicada ao que seus artistas chamam de arte indígena contemporânea.

"Remix: New Modernities in a Post-Indian World" foi uma das exposiçôes de arte contemporânea indígena que o NMAI abrigou na sede de New York, o Gustav George Heye Center, de junho até setembro de 2008. De acordo o curador da mostra Gerald McMaster, de ascendência indígena Plains Cree e Blackfoot, os quinze artistas de "Remix" objetivam em suas produçóes questionar os regimes de enunciação e autenticação das identidades tribais num mundo marcado por misturas, diásporas, hibridismo cultural e fluxos contínuos ${ }^{7}$. Re-imaginar a si mesmos e também os limites e as potencialidades de novas linguagens artísticas, contemplando reflexóes sobre commodification e mercado étnico, desejos e humores obliterados, palavras, engajamentos e imagens, vida-morte-transformação, dentre outras possibilidades de auto-definição para além das fronteiras nacionais, étnicas e culturais estiveram presentes na exposição dos "pós-indígenas"8.

Kent Monkman, o artista e o modelo da personagem Mischief fora um dos "pós-indígenas” presentes na exposição. Através de sua arte performática e de sua personagem alter-ego, o artista tem problematizado as fronteiras étnicas e de gênero decorrentes do contato entre filosofias e moralidades indígenas e ocidentais cristãs.

Como veremos, Monkman e sua Mischief conseguem adentrar os interstícios presentes entre as normatividades e discursividades elaboradas ao longo da história norte-americana sobre o lugar de suas populações indígenas, e problematizá-las através de uma política estéti- 
ca repleta de humor e ironia. Monkman fabrica um arrière-pays, um betwist-between imaginativo de que nos fala Crapanzano (2005, p. 365366,382 ), sobre os significados identitários de ser indígena num mundo contemporâneo e globalizado para além dos mecanismos de controle estereotipantes, apontados por Bhabha (2007) e Gilroy (2007), como as listas de tribos reconhecidas pelo Bureau of Indian Affairs, terras demarcadas e reservas tuteladas.

Crapanzano (2005, p. 365, 369, 372) nos fala que os horizontes narrativos, lugar da ausência e da possibilidade que viabiliza projeçóes na realidade, se dão através de uma natureza pictórica, uma cultura visual que no mundo euro-americano está extremamente vinculada ao imaginário e à imaginação. A visualidade marca uma territorialidade que funda uma identidade social, uma "cidadania" comum e uma "humanidade" compartilhada, afirma Gilroy (2007, p. 138), o que se dá através de memórias e histórias comuns, afirma Avtar Brah (2006, p. 373).

Portanto, observar as transformaçóes das representaçôes sociais sobre os indígenas e seu lugar estereotípico produzido nas mitologias da nação americana se faz necessário para entender o que Mischief e Monkman estão re-imaginando através de uma apropriação e montagem subversora (Crapanzano, 2005, p. 371). Para tanto, sigamos adiante observando algo da cultura visual que representou as populaçôes norte-americanas indígenas nos séculos XVIII e XIX.

\section{Native americans, essencialismos e estereótipos na estética colonialista dos séculos XVIII e XIX}

Segundo o historiador Hans Christian Adam (2005, p. 6-30), durante as três primeiras décadas do século XX, o fotógrafo e etnó- grafo Edward Sheriff Curtis realizou a vasta empresa de documentar a vida e os rituais dos índios norte-americanos através de fotografias e vídeos, tendo produzido mais de quarenta mil negativos fotográficos e registrado dez mil cantos tradicionais através das expediçóes que participou. Financiado pelo editor John Pierpont e estimado pelas tribos norte-americanas que viam com bons olhos sua tentativa de preservar suas histórias e memórias, a produção de Curtis se tornou uma referência imagística pioneira sobre os nativos do continente, tendo sido publicada em vinte volumes da obra "The North American Indian", publicados entre 1907 e 1930, e constituídos originalmente de 721 fotogravuras de grande formato.

Suas fotografias retratam de forma idealizada, posada e romântica os índios em cenas rituais, cotidianas e em harmonia com a natureza circundante das reservas aos quais foram confinados, tendo sido bastante criticadas pela comunidade científica de sua época, sobretudo pelos etnólogos vinculados ao American Bureau of Ethnology e o Smithsonian Institute, aponta Adam (2005 p. 17-23).

Antes de Curtis, os índios norte-americanos já haviam sido retratados por viajantes estrangeiros de passagem pelo continente americano. De acordo com a antropóloga Sonja Schierle (2005, p. 9-15), desde 1833, naturalistas como Maximilian Prince of Wield, sob o pseudônimo de Baron Von Braunsberg navegavam as águas dos rios Missouri e Yellowstone estudando os aspectos geológicos, botânicos, zoológicos e culturais do continente. Acompanhado pelo pintor de paisagens Karl Bodmer, Maximilian resolvera registrar as culturas nativas com mesma curiosidade científica orientada pelos preceitos iluministas que se dedicara aos estudos botânicos e zoológicos.

Outro renomado pintor que se dedicou a registrar intensamente as culturas nativas do continente na mesma época, George Catlin, 
se juntou à expedição Maximilian por quase um ano quando atravessaram o rio Missouri; assim como o naturalista Duke Paul Wilhelm de Württemberg que acompanhou o grupo em 1820. Após a expedição, Maximiliam fez uma seleção das aquarelas de Bodmer e as publicou no livro "Die Reise in das innere Nord-America in den Jahren 1832-34”, entre 1839 e 1841, em volumes separados cujas legendas eram orientadas sob os escritos dos diários de bordo do príncipe Maximilian.

Tal qual a linguagem pictórica do período presente na obra não apenas de Karl Bodmer e George Catlin, mas de inúmeros outros pintores românticos oitocentistas como Paul Kano, Alfred Jacob Miller, Albert Bierstadt e o grupo dos Sete, os índios (entenda-se aqui os homens indígenas) são retratados como parte da ora bucólica, ora selvagem paisagística retratada, em prosaicas imagens de perfil sempre posadas e com um olhar contemplativo, repletos de instrumentos rituais ou em cenas de batalhas históricas e caça cotidiana.

É sobre esta obra que Kent Monkman se propóe problematizar. Embora artistas como George Catlin, Karl Bodmer e Edward Curtis componham o panteão da imagística indianista norte-americana, sendo respeitados pela sua produção pioneira e relevância histórica sobretudo na história da arte norte-americana e canadense, vários artistas indígenas e mestiços como os de "Remix" têm problematizado esta herança e patrimônio, categorias que refutam acusando-as de um fardo que tem colaborado para a manutenção de estigmas e olhares folclorizantes sobre os Native Americans contemporâneos.

Ao falar sobre o dispositivo do estereótipo no poder colonial, Bhabha (2007, p. 115) aponta que visóes estereotípicas como as que apontamos aqui, têm por característica a fabricação de fantasias de origem que fundam um lugar da alteridade distante e isolado, portan- to, controlado e asséptico, evitando contágios e misturas degenerativas. Daí a natureza como lugar idílico de uma força outra, estado de infância atávica que se quer evitar. Mas quando os progressos da civilização trazem a apatia e os perigos de uma fraqueza efeminada e passiva é o estereótipo do índio enquanto força máscula da natureza que se evocará nas fantasias coloniais oitocentistas, como nas pedagogias propostas por G. Stanley Hall e nas obras de Theodore Roosevelt, apontadas por Gail Bederman (1996).

Bhabha (2007, p. 117-119) afirma ainda que a eficácia do poder e do discurso colonial está em sua teatralização, na visibilidade prazerosa que produz. Daí a recusa de Monkman desta tecnologia do estereótipo presente na visualidade pictórica do século XIX, produtora de uma diferença indígena esquadrinhada e estável, portanto, sujeitada e consequentemente constitutiva de uma subjetividade negativa e não diferenciável - alienizante e inferiorizante, diz Frantz Fanon (2008), que incitaria uma ansiedade do dominador a controlá-la/conservá-la até seu desaparecimento.

Monkman questiona não apenas o olhar eurocêntrico eivado de preceitos iluministas de raça em desaparecimento e do bom selvagem nesta produção, mas questiona o que ele chama de uma colonização da sexualidade presente nas obras deste período. A recorrência de homens indígenas em posição de chefia, a ausência de mulheres e sobretudo a quase inexistência de imagens que apresentem os "two-spirited" ou "ayekkwew" para os índios Cree canadenses relativo aos "homossexuais" e "crossdressed" indígenas é apontada como índice de genocídio cultural das tribos norte-americanas, sobretudo pelo que Monkman chama de "imperialismo cristão".

As imagens oitocentistas reafirmariam o imaginário de um ultra-macho indígena guerreiro e selvagem, afirma Monkman, descarac- 


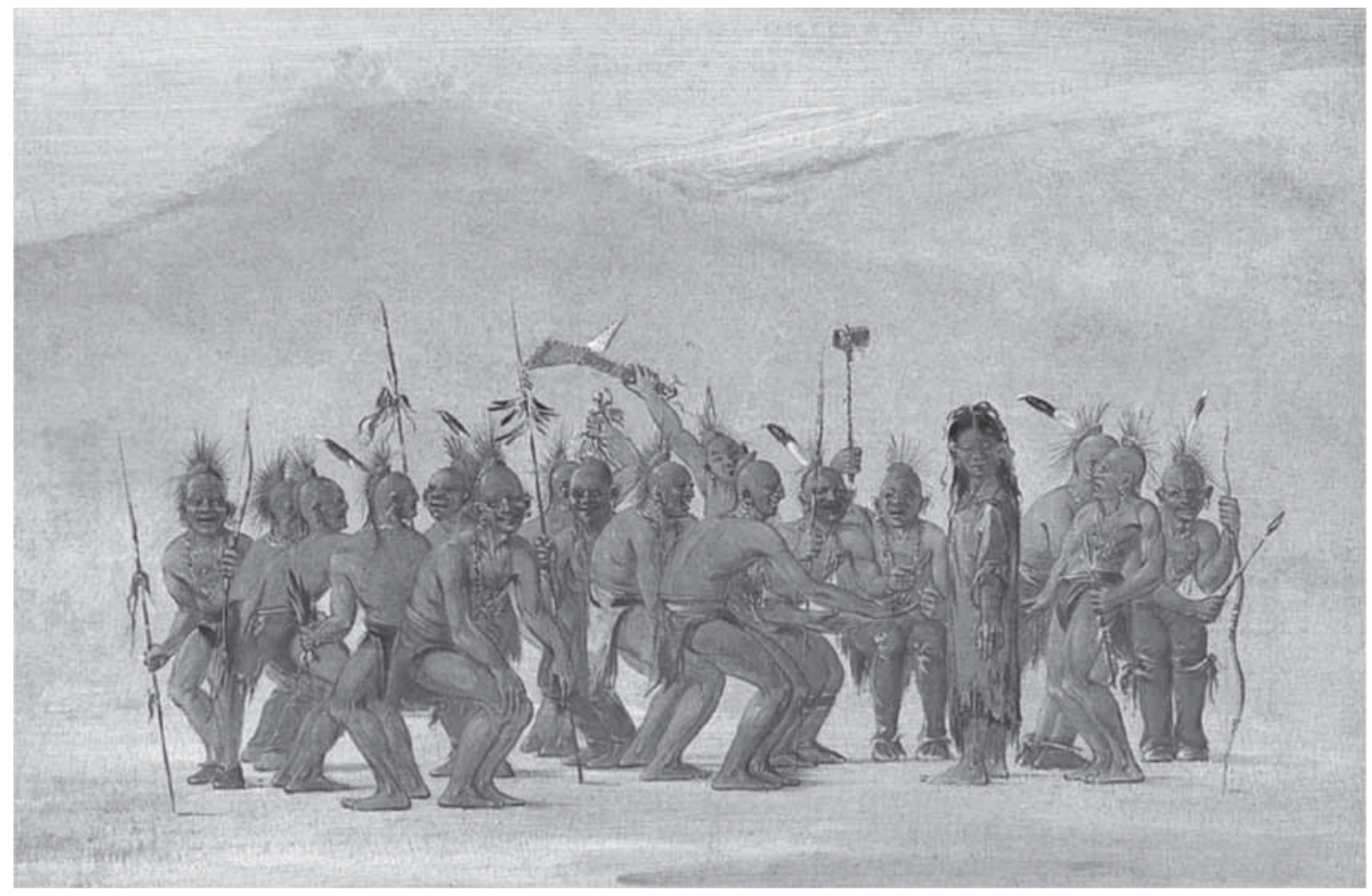

Figura 1. George Catlin. Dance to the Berache: Drawn while on the Great Plains, among the Sac and Fox Indians. 0 desenho apresenta uma dança cerimonial para celebrar a pessoa de dois espíritos. Reprodução em domínio público disponível em http://pt.wikipedia.org/wiki/ Ficheiro:Catlin_-Dance_to_the_berdache.jpg.

terizando o respeito e até certa "sacralidade" que os "two-spirited" sempre tiveram nas tribos norte-americanas como os Cree, Ojibwa, Navajo, Lakota e Winnebago (Swanson, 2005, p. 10). Com a introdução do protestantismo e o surgimento das igrejas indígenas, os "two-spirited" foram sendo alvo de estigmatização sob o termo pejorativo "berdache", termo francês de origem árabe (bardaj, que significa escravo ou prostituto), segundo a historiadora Liz Hill (2007, p. 196). Para o ativista transexual Kylan Mattias de Vries (2008, p. 63-64) o termo foi cunhado pelo jesuíta Jacques Marqhette em 1664, aparecendo também no livro "The Jesuit Relations and Allied Documents Vol. 59", publicado entre 1667 e 1669, quando os jesuítas encontraram homens iroquois vestidos em trajes femininos.

O explorador e artista George Catlin talvez tenha sido o primeiro europeu a documentar a imagem de um "two-spirited" ao retratar em seu livro de memórias publicado em 1841, "Letters and Notes on the Manners, Customs and Conditions of the North American Indians" (Goddard, 2007), uma cerimônia entre os povos Sauk e Foxes vivendo na margem oeste do lago Huron, Michigan. Em sua pintura "Dance to the Berdache" um grupo de quinze guerreiros com lanças e flechas nas mãos, circundam a personagem "two-spirited" que veste trajes femininos. Os guerreiros sorriem e emulam um menear erótico de quadris ao redor da personagem “cross-dressed" que permanece ereta e serena.

De acordo com o historiador Hamish Ion", Catlin considerou o conceito tribal dos "two-spirited" como uma degradação que deveria ser extinguida antes que fosse amplamente difundida. No entanto, Catlin reconheceu que por sua ambigüidade os "two-spirited"10 fossem 
vistos por estas tribos como dotados de certa sacralidade e poderes medicinais.

Novamente, seguindo as trilhas de Bhabha (2007) e Avtar Brah (2006), podemos pensar que as diferenças instáveis e internas - intensivas, diria Deleuze (1988), devem ser suprimidas e docilizadas enquanto identidades e subjetividades negociadas socialmente enquanto estabilidade, diferença extensiva. Nas interseccionalidades entre raça e gênero, a natureza selvagem e a etnia indígena são masculinizáveis, ao contrário do homem moderno civilizado como um jardim, potencialmente feminilizável, que se quer evitar.

\section{Erotizandoedeslocando:iconoclastias e "iconorragias" estético-políticas}

As pinturas de Monkman, no entanto, se propóem a ir além de um reclame pelos desejos, erotismos e sexualidades fronteiriços e fluídos sob a encarnação visual e performática de seu alter-ego Mischief. Há também um elogio à fatura e feitura da pintura, um elogio da cópia que aponta para a valorização desta tradição pictórica questionada, criticada e relativamente abandonada pela arte contemporânea. Ao ser entrevistado pelo crítico de cinema David Furnish (Furnish, 2006. p. 1-2) sobre seu processo criativo, Monkman afirma:

For me, it's about following a tradition in painting that has existed for centuries in which painters make copies paintings and learn through that process. So what I'm doing is taking the most spectacular landscapes that I can find and painstakingly reproducing them in a way that conceptually reclaims those landscapes. I paint the narrative in last so I have a couple of months to imagine what it's going to be. There are no "historical figures" in the scenes, quite often including my alter ego, Mischief Eagle Testickle, who is a drag-queen.
O artista canadense apresenta pinturas históricas que reproduzem um imaginário romântico e folclórico dos índios norte-americanos, porém introduzindo a sexualidade de modo a inaugurar uma erótica diferente da colecionista e orientalista oitocentista (Mitchell, 1992), instabilizando sobretudo a zona de conforto sobre as raízes e valores culturais indígenas que acredita existir entre os americanos, o que ele chama de "cowboy mythology" (Furnish,2006, p. 2).

Os deslocamentos simbólicos que Monkman realiza nos permitem evocar a ideia de diáspora trabalhada por Gilroy (2007, p. 151162). Subvertendo as fronteiras da inclusão e da exclusão, assim como mostrando que o "outro" da diferença também tem seu Outro, Monkman refuta a condição vitimizada como um essencialismo estratégico proposta por Gayatri Spivak (2010) e assume uma posição ativa e crítica através de uma política estética humorística que incita seu espectador a realizar "diásporas" simbólicas, fissurando lugares de residência e pertencimento anteriormente convencionalizados.

Filho de pai cree e mãe irlandesa e inglesa, Monkman está interessado nas narrativas perdidas, nos hibridismos culturais e na afirmação de que as culturas nativas estão vivas e não são estáticas ou "autênticas", através de uma pesquisa pictórica e performática que comunique as nuances em complexidades que acontecem entre culturas, afirma o artista em entrevista (Furnish, 2006, p. 1-2).

Rompendo com os dualismos da genealogia e da geografia, que como aponta Gilroy (2007, p. 154), marcam as construções sociais da identidade cultural, Monkman/Mischief "dissemina” tensóes e ansiedades através de sua personagem trans-cultural/trans-ontológica. E rompendo com a racionalidade nacional norte-americana em torno dos papéis e fronteiras étnicas/raciais, sexuais e de gênero entre as reservas indígenas e o mundo das galerias de arte 


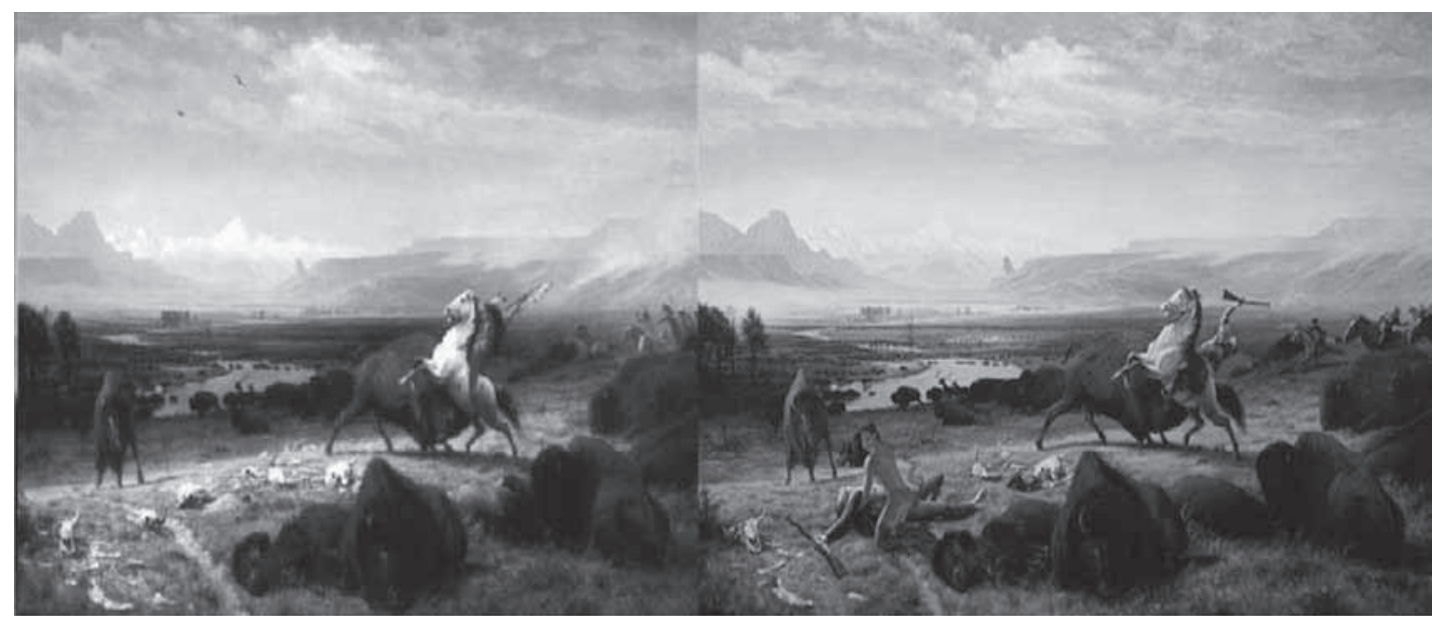

Figuras 2 e 3. Albert Bierstadt. The Last of the Buffalo. Reprodução em domínio público disponível em http://pt.wikipedia.org/wiki/ Ficheiro:The_Last_of_the_Buffalo.jpg; Kent Monkman. The Death of Adonis. Acrílico sobre tela, 2009. Imagem enviado pelo artista, direitos concedidos

contemporânea; o que Bhabha (2007, p. 198) chamou de "dissemiNação".

Desde uma série de exemplos possíveis, destaco aqui a reinvenção da pintura de Albert Bierstadt, pintor alemão radicado nos Estados Unidos durante o século XIX e um dos expoentes da Hudson River Art School. Monkman reproduz a tela "The Last of the Buffalo" substituindo o índio que caça o búfalo por um cowboy portando uma espingarda nas mãos, que luta com o animal cuja pose remete à escultura "The Death of Adonis", de Guiseppe Mazzuoli, em que o amante da deusa Afrodite é abatido por um javali. Nesta pintura de Monkman de mesmo nome, Mischief aparece socorrendo um soldado branco e loiro desfalecido. Ao fundo observa-se outros cowboys repletos de maneirismos corporais, atingidos ou cavalgando.

Poderíamos dizer que os cowboys que aparecem feminilizados/passivos nos "intercursos poéticos" de Monkman, o são pelo "contágio" da presença de Mischief, protagonista em quase todas as telas. "Contágios" e inversóes simbólicas que estariam presentes também na pintura europeia dos séculos XVIII e XIX, em que havia uma tara pela corporeidade negra feminina como índice de selvageria e lascívia (Gilman, 1985, p. 79-93).
Nestas pinturas oitocentistas, sobretudo, são retratadas submissas criadas negras representadas ao lado de madeimoselles brancas, em telas como "Olympia" de Manet, "The Servant" de Von Bayros ou "The Beloved, or the Bride" de Rossetti. Gilman (1985) concebe-as como um duplo/sombra das madeimoselles brancas, potencialmente corruptoras destas últimas com sua lascívia e sexualidade exacerbada. Mischiefé na obra de Monkman a grande chefe indígena produtora de travessuras sexuais e inter-raciais, artista e "arteira", criativa mas perigosa; como dubiamente indica seu nome.

Em obras como "Artist and Model” (2003), e "Earth and Heaven" (2001), o caráter trickster e humorístico do artista que se confunde com sua personagem alter-ego se revela ao introduzir colonizador e colonizado sob papéis invertidos. Em "Artist and Model", Mischief aparece portando um cavalete onde pinta seu amante loiro Buffalo Boy que está nu com o pênis ereto, eivado de flechas, portando um chapéu e assemelhando-se a São Sebastião, ícone pop da cultura queer. Já em "Earth and Heaven”, Mischief aparece com trajes masculinos e sem salto alto, sodomizando um cowboy aprisionado que nos remete a um estupro, sob o olhar de um 


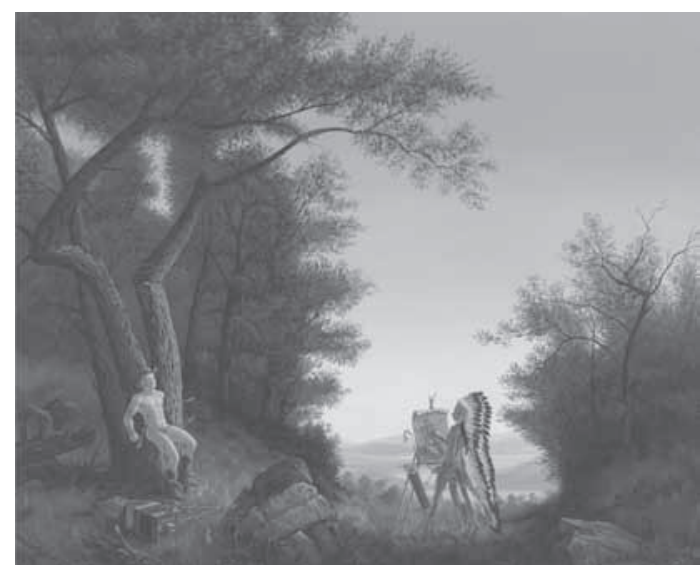

Figura 4. Kent Monkman. Artist \& Model. Acrílico sobre tela. Imagem enviada pelo artista, direitos concedidos.

búfalo flechado numa paisagem nimbosa em que uma única fonte de luz saída do céu recai sobre os personagens.

As expressóes ora masculinas, ora femininas da personagem de Monkman, de forma a questionar os limites e a naturalidade dos papéis sexuais e de gêneros na performatização de Mischief poderiam ser aproximados às reflexôes de Judith Butler (2002, p. 162-163) no tocante à visibilização do que a autora chama de "corpos abjetos", fronteiriços e sem materialidade definida, performáticos e processuais, sem a legitimidade heteronormativa dos corpos instituídos com papéis de gênero delimitados em unidades discretas (Butler, 1988). Na trilha de Foucault, Butler (2002, p. 161) afirma que se deve dar discursividade aos corpos abjetos, híbridos e fronteiriços, como o de Monkman/ Mischief, e materializá-los através de uma imaginação performática que permita constituir novas ontologias corporais, sexuais e de gênero, de forma ativa, interativa, relacional.

E é Halberstam (1998) quem radicaliza o questionamento das unidades discretas sexuais e de gênero que fabricam corpos abjetos como seu duplo ou sombra, ao falar de masculinidades femininas (e poderíamos falar ainda de feminilidades masculinas), se pensarmos os jogos de Monkman/Mischief, ao desnaturalizar as cons-

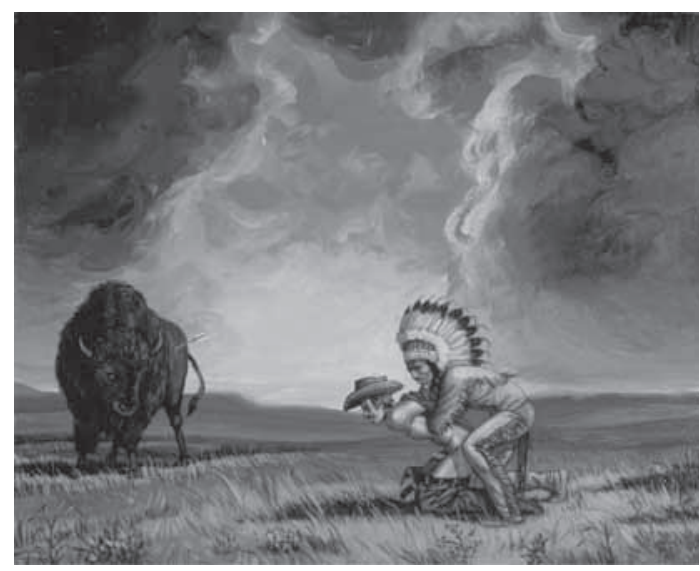

Figura 5. Kent Monkman. Earth \& Heaven. Acrílico sobre tela. Imagem enviada pelo artista, direitos concedidos.

truçóes de sexo/gênero em sua historicidade e localidade etnocêntrica convertidas numa universalidade cultural como ontologia metafísica a priori. Para Judith Halberstam (1998), a associação entre masculinidade e o sexo masculino não deve ser naturalizada e/ou universalizada, porque é construída e localizada histórica e culturalmente, o que nos permite a re-imaginação e a reivindicação de feminilidades masculinas e vice-versa.

Estas subversóes/inversóes simbólicas parecem apontar para uma negociada ruptura dos limites dos poderes convencionalizados para além de dicotomias como colonizador/colonizado, domínio/submissão, sujeito/objeto, artista/modelo, cowboy/indígena, macho/fêmea, ativo/passivo. Uma iconoclastia política que é "iconorragia" porque é guerra de imagens, diria Latour (2002). Na relação entre Buffalo Boy e Mischief, por exemplo, podemos recordar outra relação de inversão e performatização de papéis sexuais e de gênero, como a do casal vitoriano com práticas sado-masoquistas Hannah Cullwick e Arthur Munby, estudados por Anne McClintock (2003).

Agenciando uma economia de conversões recíprocas através da performatização de diversos papéis de gênero, de classe e raciais, o casal que era composto por um homem branco aristocrático que se apaixonara por uma mulher 
branca da classe trabalhadora e que se recusava ao matrimônio, manteve uma conjugalidade fetichista por anos, positivando desigualdades e hierarquias, visibilizando o poder e a alienação sobre os corpos através de seus "jogos de fantasia”, afirma McClintcock (2003, p. 23-26), ampliando imaginários sobre os papéis sociais das personagens que emulavam. A poética de Monkman vai nesta direção. Sobretudo num vetor que aponta para uma condição agentiva e não vitimizada, sobretudo dessencializada, aponta (Gonick, 2009):

I'm interested in communicating all the nuissances and complexities that happen between the two cultures. You know, native cultures are not static and never have been [...] We are still here, and we are not victims. We're capable of evolving as cultures. It's about expressing the beauty that's there.

Influenciado por Goya, Francis Bacon e Tom of Finland, Monkman apresenta aspectos fetichistas e sado-masoquistas em seu trabalho que mobilizaram o diretor de cinema Noam Gonick em entrevista publicada na revista " $\mathrm{Ca}$ nadian Dimension” (Gonick, Op. cit.), a indagar o artista sobre os riscos de uma erotização humorística do genocídio indígena através dos seus trabalhos. Monkman destaca sua pretensão de deslocar e reverter as relaçóes de poder e relembrou o humor na tradição storyteller de myth-making não apenas entre os Cree, mas dentre outras tribos do continente americano:

I don't think I'm eroticizing genocide at all. I think what I'm presenting is an empowered perspective and an empowered way of life, looking at our own sexuality; and yes I'm playing with traditional power relationships and reversing them, but it's certainly not about sexualizing or making fun of genocide. No one has ever raised that question or issue with me [...]
There's actually, if you look at traditional Aboriginal stories, a lot of bawdy humour, a lot of sexual humour. It's there. It's part of our culture (Gonick, Op. cit.).

\section{Convençóes, inversóes, invençóes}

Kent Monkman retirou seu alter ego das telas e lhe deu agência, poderíamos ousar dizer tal qual uma "distributed person" de que nos fala Alfred Gell (1998). Mischief Eagle Testicke foi pela $1^{\mathrm{a}}$. vez encenada como uma performance artística, afirma Swanson (2005, p. 3), em 2004, na McMichael Canadian Art Collection Gallery.

Inspirando-se nas paisagens pintadas pelo Grupo dos Sete e no filme "In the Land of the Headhunter" (1914) de Edward Curtis, Mischief chegou com seu cavalo branco, cocar e adereços personalizados Louis Vuitton e Hudson Bay Company, juntamente a dois homens, um deles vestindo-se como Robin Hood e outro como o religioso Frei Tuck (Swanson, 2005, p. 3-4). Após um concurso de arco e flecha ela interagiu com os dois personagens de modo a pesquisar espécimes do homem branco em seu habitat natural.

Intitulada "Taxonomy of the White Men" esta performance se aproxima de "Group of Seven Inches", onde homens são banhados com whisky e obrigados a posarem para a persona trickster de Monkman em sua tara pictórica.

Aqui é o homem branco o pouco civilizado e rude e é Mischief a encarnação de um poder glam na ativação performática de um gênero trans e uma sexualidade fluída que reinventa o lugar dos berdaches através de uma antropologia reversa sob os moldes nativos, tal qual nos fala Roy Wagner (1981), mas também das inversóes hierárquicas mobilizadas pelo casal Cullwick-Munby, estudadas por McClintock (2003, p. 23). 


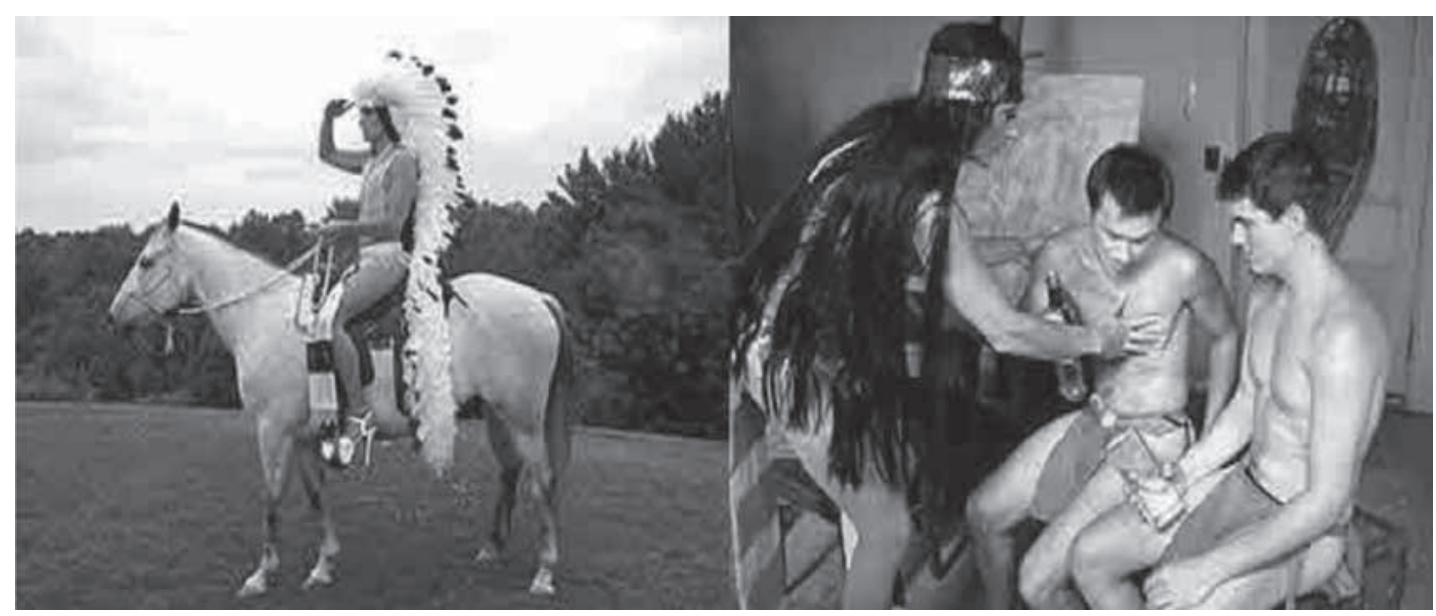

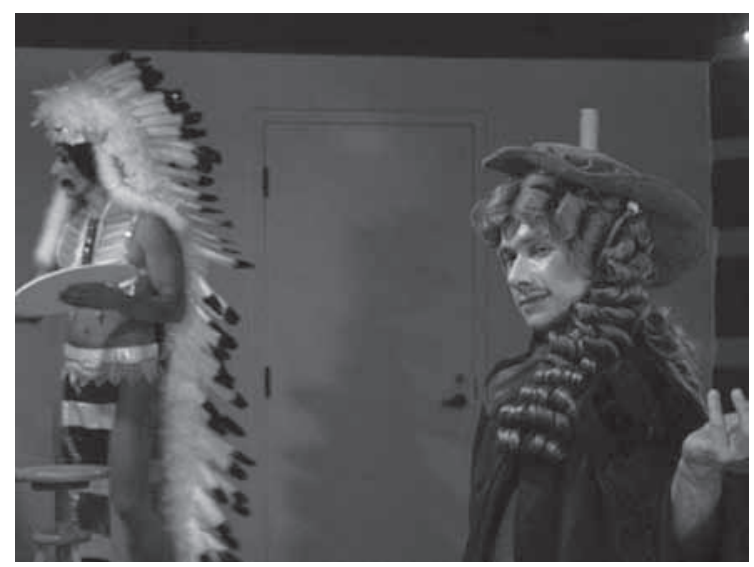

Vale notar que além de cross-dressed e transgênero, MischieflMonkman é mestiça/o. Além de possuir os espíritos masculino e feminino típico dos "two-spirited" tribais, a/o personagem é cree e também canadense, irlandesa e inglesa, sendo portanto uma "half-breed", palavra utilizada por muitas tribos norte-americanas para se referir a índios com ascendência misturada. A própria Mischief, diga-se de passagem, foi inspirada na canção "half-breed" da cantora norte-americana Cher, hit nos anos 70. Cher, que possui ascendência Cherokee reclama na letra da canção que sempre odiou ser vista como "mestiça", índia pelos brancos, e branca pelos índios ${ }^{11}$ :

My father married a pure Cherokee

My mother's people were ashamed of me

The Indians said I was white by law
Figuras 6, 7 e 8. Kent Monkman. Group of Seven Inches. Performance, 2004. McMichael Canadian Art Gallery. Imagem enviada pelo artista, direitos concedidos

The white man always called "Indian Squaw" Half-breed, that's all I ever heard Half-breed, how I learned to hate the word Half-breed, she's no good they warned

Both sides were against me since the day I was born

We never settled, went from town to town When you're not welcome you don't hang around

The other children always laughed at me "Give her a feather, she's a Cherokee" We weren't accepted and I felt ashamed Nineteen I left them, tell me who's to blame My life since then has been from man to man But I can't run away from what I am.

O fato de Mischief ser mestiça nos remete a toda sorte de ideologias racialistas e racistas 


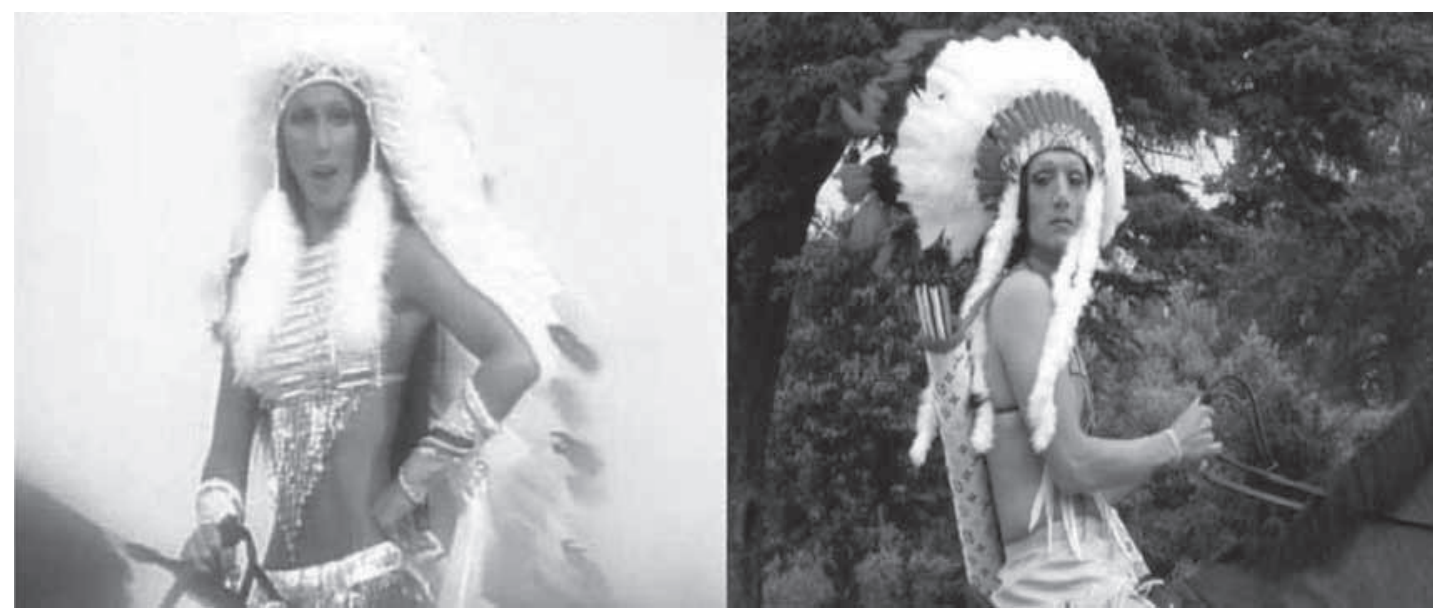

Figuras 9 e 10. Cher. Fragmento do videoclipe da canção Half-Breed; Kent Monkman. Mischief, Eagle Share Testickle. Imagens enviadas pelo artista, direitos concedidos.

produzidas ao longo do século XIX, assim como as subsequentes teorias críticas à noção de raça e a diferentes modalidades de racismo intrínseco e extrínseco, como apontadas por Appiah (1997, p. 55-57). Evocando as teorias de W. E. B. Du Bois, o "pai" do pan-africanismo e sua crítica a noção biologizante de raça na afirmação de que raça implicaria em uma história comum que permitisse conceber uma pan-africanidade, Appiah se afasta de Du Bois ao questionar a própria trajetória do teórico para nos fazer pensar em histórias hibridizadas e múltiplas, o que lhe permite apontar Du Bois como um racista extrínseco em sua teoria de cunho moralista e ontologizante.

Mischief, "reencarnação" da half-breed de Cher, incorpora a inversáo de papéis para acentuar e visibilizar a natureza racista das classificaçôes oficiais governamentais e as que operam no imaginário cotidiano diferenciando índios, brancos, negros, gays, héteros, bissexuais, mestiços, americanos, dentre outras demarcaçōes sociais $^{12}$. Podemos ainda pensar que, tal como Appiah (1997, p. 75) que acaba por negar a raça enquanto conceito que positiva e dá voz à novos sujeitos de direito, Mischief parece questionar fronteiras e essencializaçóes moralistas que acabam por reafirmar diferenças ao invés de democratizar acessos e questionar desigualdades através das semelhanças.

Personificando uma confluência entre diferenças, MischieflMonkman questiona o fantasma da espetacularizaçáo dos mundos indígenas se apresentando nas galerias de arte e museus do Canadá e dos Estados Unidos, onde lhe é possível visibilizar a mercantilização das diferenças indígenas enquanto obras de arte, além de criticar as autoridades de demarcaçáo e autenticaçáo da "verdadeira arte" e da "arte nativa" nestes países.

\section{Consideraçóes Finais: O Triunfo de Mischief}

Mas de qual diferença a ser construída exatamente estaria Kent Monkman/Mischief falando? Que dispositivos e biopoderes em torno da sexualidade (Foucault, 2006) ele/ela pretende engendrar ao conciliar um "myth-making" indígena que concebe "two spirited" com outro "myth-making" ocidental moderno que classifica e esquadrinha gays, bissexuais e héteros com corpos, desejos e psiques vistos ora como culturalmente, ora como naturalmente distintos?

Monkman afirma na entrevista concedida a David Furnish (2006, p. 2) que "you can exist in 

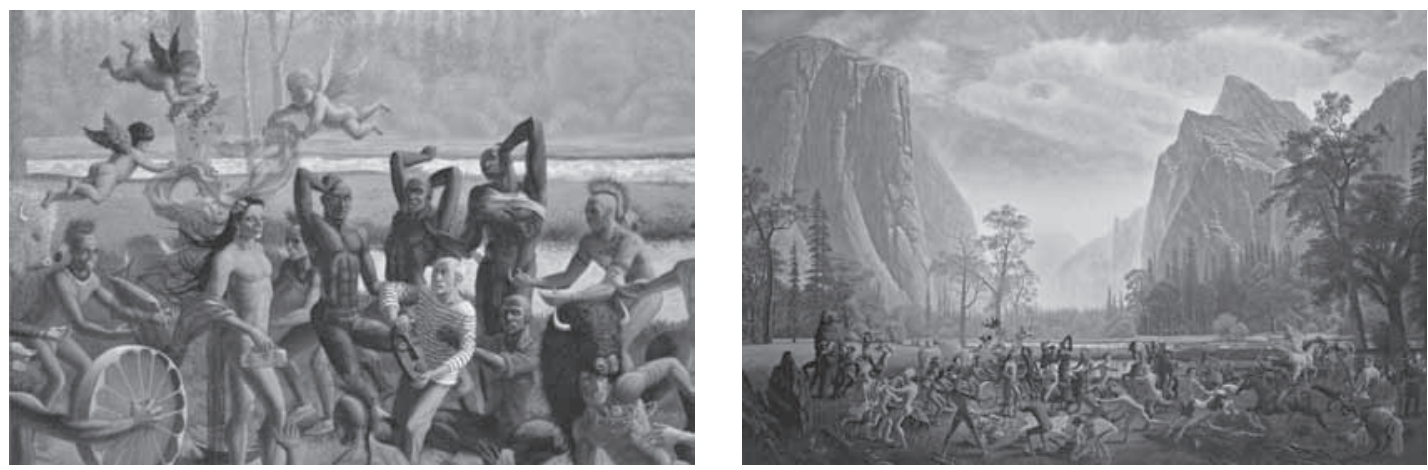

Figuras 11 e 12. Kent Monkman. The Triumph of Mischief. Acrylic on canvas. 2007. Imagens enviadas pelo artista, direitos concedidos.

the modern world and still carry your values and your roots and your culture with you" tal qual Sahlins $(1997$; 2004) nos fala sobre os renascimentos indígenas decorrentes do clash com o mundo ocidental moderno, indigenizado também por sua vez em diversas zonas de contato mundo afora (Clifford, 1997; Bhabha, 2007).

Mas será que a personificação de Mischief na performance de Monkman seria espaço para formulaçōes multi-culturalistas entre fronteiras étnicas já estudadas por Friedrik Barth (2000) e as decorrências exigências de novos sujeitos de direito entre posiçōes ora pragmáticas, como a de Rorty (2002), ora relativistas, como a de Geertz (2001)? Seria um caso do que Carneiro da Cunha (2009) chamou de "cultura com aspas" ${ }^{13}$ ? Ou para um clash de mundos distintos, multi-naturezas, se pensarmos a produçáo da diferença enquanto ontologia singular e múltiplos mundos, a seguir os trabalhos de Viveiros de Castro (2002a; 2002b; 2004) ${ }^{14}$ e Philippe Descola (2005)? Haveria aos moldes de Bruno Latour (1994) uma crítica ao etnocentrismo modernista e suas classificaçóes de mundo nas "utopias" de Kent Monkman?

Questôes epistemológicas e ontológicas de difícil saída como essas são a pauta da vez da antropologia contemporânea. A obra de Kent Monkman, assim como de outros artistas indígenas que tem problematizado as fronteiras em torno de suas condições existenciais e produção artística, talvez nos permitam uma chave alternativa para pensar as soluçóes nativas diante de impasses como os levantados pela antropologia contemporânea, que de certa forma refletem a busca de uma "caosmose", tal qual enuncia Guattari (1992), uma nova ecologia de mundos virtuais, através de experimentaçóes artísticas como trunfo e possível triunfo.

Entre consumismo e moda, cultura de massa e música pop, estética queer e valores tradicionais indígenas como os "two-spirited", Kent Monkman inventa uma "antropologia" que problematiza os limites entre masculino e feminino, passado e presente, colonizador e colonizado, criador e criatura, sujeito do desejo e objeto do desejo, subvertendo os marcadores sociais das fantasias de controle nacionais ${ }^{15}$. $\mathrm{Na}$ obra "Triumph of Mischief" (2007), índios, búfalos, minotauros, brancos, um possível Picasso segurando uma máscara nas mãos, negros, ursos, anjos, faunos e ciclopes jogam, brincam, pelejam e confraternizam uma "comunidade imaginada" (Anderson, 2008) que é uma antropologia possível sob o olhar atento de Mischief, que desde a tela nos observa.

Inverted assails: Performance and politics

\section{in the art of Kent Monkman/Misichief.}

abstract Between 2007 and 2008, was on display at the National Museum of the American Indian, the exhibition "Remix: New Modernities in a Post-Indian World" composed of 15 indigenous artists, who through their work questioned the boundaries of authenticity, creativity of the contemporary In- 
dian, and about the sense of asserting themselves as indigenous today. Black Indians, Gay Native, dilemmas of cyberculture, among other images were present at the remixes of "post-Indian" art, which experimented with new meanings about the body, gender, ethnicity, territoriality and time. The aim of this paper is to discuss the production of Kent Monkman - a gay, Cree descent - since this exhibition up to today. By means of his drag-queen half-breed Miss Chief character - inspired on the singer Cher and constituted in his paintings, photographs and video art - Monkman makes performances which reinvent the nineteenth century romantic imagery, one that inscribes the "noble savage" in sublime landscapes, by questioning stereotypes of sexuality during the European conquest and exploring relationships with xenophobia and imperialism. Criticized as "erotic genocide", the "trickster", Monkman affirms he aims to reverse sexual roles and powers of traditional indigenous people to expand reflection on the "third gender" among the indigenous worlds in North-America. Evoking the "two-spirited", criticizing the ultra-macho indigenous mythology by highlighting the "perversions" between Indigenous and White people; Monkman asks: who "dislocates" who?

keywords Indianity/Indianness. Sexuality. Performance.

\section{Notas}

1. Agradeço a Laura Moutinho (PPGAS-USP), Pedro Peixoto Ferreira (IFCH-UNICAMP) e Ilana Goldstein (IFCH-UNICAMP) pela leitura atenciosa e crítica e pelas sugestôes bibliográficas que resultaram na presente versão deste texto. Agradeço também e, em especial, a Brad Tinmouth e Kent Monkman pela concessão do direito das imagens publicadas neste artigo.

2. As informaçóes que permitiram este recurso de imaginação histórica nos termos da historiadora Bárbara Tuchman (1991) foram extraídas do site da McMichael Canadian Art Gallery: http:// www.mcmichael.com/about/history.cfm.
3. De acordo com o livro Do All Indians Lives in Tipis? Questions and Answers from the National Museum of the American Indian, editado por Sally Barrows, não existe consenso acerca do uso do termo politicamente correto. Portanto "tribe" ou "nation" são usados simultaneamente, assim como "Indian", "American Indian", "Native American”, "Indigenous people" são alguns dos termos usados por indígenas e nâo-indígenas na América do Norte, embora algumas tribos do Canadá prefiram o termo "First Nation".

4. As informaçóes que permitiram este recurso de imaginação histórica nos termos da historiadora Bárbara Tuchman (1991) foram extraídas do site do artista: http://kentmonkman.com/works. php?page=performance\&start $=1 \#$

5. Uso a palavra "antropologia" aqui de forma lato sensu. Kent Monkman não é antropólogo de formação, tampouco constituiu uma trajetória acadêmica na área. No entanto, poderíamos dizer que ele produz uma cosmologia ou ontologia singular, e portanto uma antropologia, através de sua produçấo artística se nos aproximamos das proposiçóes de Viveiros de Castro (2002a) sobre a relatividade dos divisores epistemológico-ontológico que constituem perspectivas antropológicas e nativas como produçóes mútuas, contínuas e reversivas constituídas relacionamente.

6. Os índios que compóem os principais cargos da instituição desde à diretoria até seus curadores permanentes são oriundos das tribos reconhecidas pelo subsídio do Bureau of Indian Affairs, a principal instituição do governo americano voltada para a populaçáo indígena, vinculada ao U.S. Department of Interior, que estabelecida desde 1824, administra atualmente 55 milhôes de acres de superfície e 57 milhóes de acres de minerais das 564 tribos reconhecidas nos EUA e no Alasca.

7. Os 15 artistas em questão são: Dustinn Craig (White Mountain Apache/Navajo), Fausto Fernandez (Mexican/American), Luis Gutierrez (Mexican/American), David Hannan (Métis), Gregory Lomayesva (Hopi/Hispanic), Brian Miller (Mohawk), Franco Mondini-Ruiz (Tejano/Italian), Kent Monkman (Cree/English/ Irish), Nadia Myre (Anishinaabe), Alan Natachu (Zuni/Laguna), Hector Ruiz (Kickapoo/ Mexican/American), Anna Tsouhlarakis (Na- 
vajo/Creek/Greek), Bernard Williams (African American/Native Ancestry), Kade Twist (Cherokee) e Steven Yazzie (Navajo/Laguna Pueblo/ Welsh). Cf. BERTOLOSSI, Leonardo. 2010. Diferentes, Iguais: A Pan-Indianidade do $\mathrm{Na}$ tional Museum of the American Indian e suas Variaçôes. Dissertação apresentada ao PPGAS-Museu Nacional-UFRJ. 238p.

8. Informações extraídas do site da exposição http://www.nmai.si.edu/exhibitions/remix/, do catálogo da exposição: BAKER, Joe; McMASTER, Gerald (eds.). 2007. Remix: New Modernities in a Post-Indian World. Washington D.C/ New York/Phoenix: NMAI Editions/Smithsonian Institute/Heard Museum.

9. Informação extraída do texto do autor publicado no site: http://thedrummersrevenge.wordpress. com/2007/06/13/8/

10. Poderíamos tentar construir uma comparação com o divíduo de que nos fala Strathern para pensar as noçóes de gênero nas tribos melanésias, por exemplo. Strathern (2006) afirma que a pessoa melanésia é andrógina e tudo é dual, relacional e parcial nesta antropologia nativa, porque não se fecha em si mesmo. Não há totalidade formada por partes. Tudo é simultaneamente "partes" e "conjuntos", pessoas, gêneros e coisas distribuídas e compósitas em si e entre si, que ora personificam uma dada posição/perspectiva parcial de gênero/espécie ao eclipsar as outras relaçóes internas transespecíficas/transgêneros existentes.

11. Letra da canção extraída do site da cantora Cher: http://www.cherworld.com/lyrics/halfbreed.htm.

12. De acordo com Eleanor Heartney (Apud. Baker, McMaster, 2007, p. 38, a nação Cherokee votou a exclusão de membros da tribo descendentes de escravos africanos. Pretende-se revogar a identidade Cherokee dos membros com parcela étnica African Native American ainda que eles já sejam inscritos no critério de aceitação de sócios tribais previsto na lei Dawed Rolls de 1900, que exigia a morada em terras demarcadas ).

13. Esta apropriação consciente, performática e posicionada da palavra cultura pelos índios alhures sob suas inventividades específicas é chamada por Manoela Carneiro de Cunha (2009) de "cultura com aspas". A autora difere a noção antropológica de cultura que entende como esquemas interiorizados, produzidos e compartilhados através de relações sociais específicas da noção de "cultura" que concebe como agenciamento performativo, reflexivo e político de uma dada identidade social e cultural (Cunha, 2009, p. 313). De acordo com a autora, ao invés de uma "cultura em si", é como se os índios reclamassem, uma "cultura para si", se pensarmos em termos marxistas. O que se dá neste processo ambíguo, tenso e em andamento neste momento, afirma, é que a "cultura" intervém sobre a cultura e vice-versa, numa "culturalização" da cultura indígena e na indigenização cultural da "cultura" interétnica.

14. Na direção de uma transhumanidade está a antropologia perspectivista de Eduardo Viveiros de Castro. Seguindo a pista de Lévi-Strauss em suas "Mitológicas" para pensar a "fluidez" entre natureza e cultura, ou ainda entre humanidade e animalidade, Viveiros de Castro (2002b) intensificou este argumento a partir da constatação de que em diversas ontologias nativas do Novo Mundo ou das Terras Baixas da América do Sul, o mundo é povoado por um número indeterminado de espécies dotadas de consciência e cultura, ou seja, características associadas ocidentalmente à espécie e ao espírito humano. Para o perspectivismo ameríndio de Viveiros de Castro não é a "animalidade" o nódulo simetrizador entre homens e a natureza animal ou vegetal, mas sim a "humanidade". Tudo é humano do seu próprio ponto de vista, perspectiva ou mundo singular. O que varia é o índice das relaçóes da perspectiva no mundo, ou seja, o corpo, tal qual uma roupagem natural desta humanidade ontológica. Animais desde a sua perspectiva são tão humanos e agentivos quanto os homens, vistos pelos primeiros como seus animais. Ou ainda: humanos são "ex-animais" controlados pela cultura contra-inventada pelo controle/invenção da natureza, enquanto os animais são "ex-humanos" porque têm sua humanidade escamoteada pela máscara animal que os constitui. Nesta antropologia nativa, para citar um exemplo, onças veem o sangue de outros animais como cerveja de mandioca, o barreiro em que se encontram as antas é visto como uma grande casa cerimonial, e os grilos que os espectros dos mortos comem são vistos por estes como peixes assados etc. Seres transespecíficos que conseguem transitar entre diferentes perspectivas, 
como é o caso dos xamãs, são os que traduzem os saberes entre os diferentes mundos. Se a natureza é tão variável quanto a cultura, já que do ponto de vista do perspectivismo ameríndio o que varia é a natureza (se considerarmos que a cultura e/ou a humanidade é comum a todas as espécies), não podemos mais falar de um "multiculturalismo" ou de um mundo plural (com uma natureza inata e estável); mas de um mundo multinaturalista. É importante notar que no perspectivismo tal qual um relacionalismo transespecífico, "natureza" ou "cultura", ou ainda, "humanidade" ou "animalidade", não existem isoladamente, não são nominaçôes essenciais, entes ou substâncias transcendentais. São posições pronominais, perspectivas e agenciadoras. Um mundo de diferenças intensivas e extensivas (Deleuze, 1988), intra e extra corpóreas que permitem o pensamento ameríndio "conceber brancos como aqueles que deixaram de ser índios", enquanto a mitologia ocidental "concebe aos índios como o passado dos homens brancos", para citar um exemplo. Lévi-Strauss já havia mencionado uma "anedota" antropológica que no período do contato colonizador, enquanto os brancos tentavam descobrir se os índios tinham alma, estes últimos se indagavam se os corpos europeus eram iguais aos indígenas. Seguindo o perspectivismo de Viveiros de Castro (2004), o relacionar Ameríndio é uma troca de "antropologias". Tais "antropologias" devem ser entendidas como mundos singulares, naturezas ou ontologias distintas, um multinaturalismo ou relativismo natural. Ao contrário do multiculturalismo que supóe trocas de relatividades culturais de uma natureza comum universal inscrita na mente ou numa condição humana, uma ontologia comum e variável; as relaçóes enquanto traduçóes Ameríndias impóem uma comparação entre ontologias distintas. Estendendo o pensamento ameríndio para dentro da antropologia e aproximando-se da dialética "convenção-invenção" proposta por Wagner (2010), Viveiros de Castro perspectiviza também as posições pronominais (e não essenciais) do antropólogo e do nativo. Para ele ambos são/contém potencialmente os dois lados desta dicotomia recursiva nos contatos/contágios desta economia relacional, instrumentalizada metodologicamente como um "exagerar as diferenças" que localiza a "etno-antropologia" do perspectivismo como uma tradução que é comparação entre diferentes "antropologias". Benjamin nos fala que o bom tradutor trai a língua a que se destina a tradução e não a língua de origem. Na tradução perspectivista não há traição porque não há origem, só existe a objetificação da equivocação - que funda a relação pela diferença de perspectiva. Novamente, esta confluência entre diferenças não é melancolia e perda como nas teorias da traduçáo ocidentais; mas é potência que permite recortar um espaço epistemológico comum entre diferentes ontologias e seus recíprocos etnocentrismos, através de uma comunicação disjuntiva que é controle de suas inte-tradutibilidades. As diferenças diferem, podendo ser intensivas e extensivas, intraespecíficas ou extra-específicas, não sendo portanto possível falar de alguma univocação. É no espaço da equivocaçáo enquanto comunicação entre diferenciaçôes que é possível criar uma tradução sem síntese e sem consenso entre mundos; através não do elogio da representação, mas da evocação das diferenças para uma transducçáo que aponte todos os termos em relação.

15. Artistas indígenas como James Luna (Luiseño) e Hulleah J. Tsinhnahjinnie (Dine/Seminole/Muscogee) produziram trabalhos em que questionam os critérios cristalizados de demarcação de indianidades autênticas. Tsinhnahjinnie aparece com o rosto repleto de medidas e números como uma resposta ao Indian Arts and Crafts of 1990, em que indígenas trabalhavam junto ao governo na demarcação das fronteiras da verdadeira Native art americana. Luna é apresentado através de sua performance "The Artifact Piece", exibida originalmente em 1987, no Museum of Man em San Diego, onde coloca seu próprio corpo numa vitrine, questionando a exibição de culturas nativas nos museus como mortas ou como sendo apenas parte do passado. Cf. BERTOLOSSI, Leonardo. 2010. Diferentes, Iguais: A Pan-Indianidade do National Museum of the American Indian e suas Variações. Dissertação apresentada ao PPGAS-Museu Nacional-UFRJ. 238p. 


\section{Referências bibliográficas}

ADAM, Hans Christian. "Edward Curtis et les Indiens d'Amérique du Nord”. In: CURTIS, E.. Les Indiens D’Amérique Du Nord. Paris: Taschen GmbH, 2005. p. 6-30.

ANDERSON, Benedict. Comunidades Imaginadas. Tradução de Denise Bottman. São Paulo: Companhia das Letras, [1983] 2008.

APPIAH, Kwame Anthony. "A invenção da África; Ilusões de Raça”. In: Na Casa do Meu Pai: A África na Filosofia da Cultura. Rio de Janeiro: Contraponto, 1997. p. 19-51, 53-76.

BAKER, Joe; McMASTER, Gerald (eds.). Remix: New Modernities in a Post-Indian World. Washington D.C/ New York/Phoenix: NMAI Editions/Smithsonian Institute/Heard Museum, 2007.

BARTH, Fredrik. "Os Grupos Étnicos e suas Fronteiras". In: O Guru, o Iniciador e outras Variaçöes Antropológicas. Rio de Janeiro: Contracapa, 2000. p. 25-67.

BEDERMAN, Gail. "Teaching Our Sons to Do What We Have Been Teaching the Savages to Avoid”: G. Stanley Hall, Racial Recapitulation, and the Neurasthenic Paradox; Theodore Roosevelt: Manhood, Nation, and "Civilization". In: Manliness \& Civilization: A Cultural History of Gender and Race in the United States, 18801917. Chicago/London: The University of Chicago Press, 1996. p. 77-120, 170-215.

BERTOLOSSI, Leonardo. Diferentes, Iguais: A Pan-Indianidade do National Museum of the American Indian e suas Variaçôes. Dissertação (Mestrado) - Museu Nacional, Universidade Feredal do Rio de Janeiro, Rio de Janeiro, 2010.

BHABHA, Homi. "A Outra Questão: O Estereótipo, a Discriminação e o Discurso do Colonialismo; DissemiNação: Diferença Cultural e Nonsense Colonial”. In: O Local da Cultura. Tradução de Myriam Ávila, Eliana L. L. Reis e Gláucia R. Gonçalves. Belo Horizonte: EDUFMG, 2007 p. 105-128, 198-238.

BRAH, Avtar. Diferença, Diversidade, Diferenciação. Cadernos Pagu, Campinas n. 26, Jan/Jun, 2006. p. 329-376.

BUTLER, Judith. Performative Acts and Gender Constitution: An Essay in Phenomenology and Feminist Theory. Theatre Journal. Baltimore (Maryland), v. 40, n. 4,1988 p. 1-11.

; PRINS, Baukje; MEIJER, Irene Costera. Como os Corpos se Tornam Matéria: Entrevista com Judith Butler. Estudos Feministas, Florianópolis (SC), v. 10, n. 1, 2002 . p. 155-167.
CLIFFORD, James. Routes: Travel and Translation in the Late Twentieth Century. Cambridge, Massachussets: Harvard University Press, 1997.

CRAPANZANO, Vincent. Horizontes Imaginativos e o Aquém e Além. Revista de Antropologia. São Paulo-USP. V. 48, n. 1, 2005. p. 363-384.

CARNEIRO DA CUNHA, Manoela. Cultura com Aspas. São Paulo: CosacNaify, 2009.

DELEUZE, Gilles. Diferença e Repetição. Tradução de Luiz Orlandi e Roberto Machado. Rio de Janeiro: Graal, 1988

DESCOLA, Philippe. Par-delà Nature et Culture. Paris: Gallimard, 2005.

FANON, Frantz. "Sobre o Pretenso Complexo de Dependência do Colonizado". In: Pele Negra, Máscaras Brancas. Tradução de Renato Silveira. Salvador: EDUFBA, 2008 p. 83-101.

FOUCAULT, Michel. História da Sexualidade V.1: $A$ Vontade de Saber. Tradução de Maria Thereza da Costa Albuquerque e J. A. Guilhon de Albuquerque. São Paulo: Graal, 2006.

FURNISH, David. Kent Monkman: The Canadian artist Who is exploding the mythology of the West - One Brushstroke at a time. Interview Magazine. 2006. p. 1-2. GEERTZ, Clifford. "Os Usos da Diversidade". In: Nova Luz sobre a Antropologia. Tradução de Vera Ribeiro. Rio de Janeiro: Jorge Zahar Editor, 2001. p. 68-85.

GELL, Alfred. Art and Agency: An Anthropological Theory. Oxford: Claredon Press, 1998.

GILMAN, Sander L. "The Hottentot and the Prostitute: Toward and Iconography of Female Sexuality; Black Sexuality and Modern Consciousness". In: Difference and Pathology: Stereotypes of Sexuality, Race, and Madness. Ithaca/London: Cornell University Press, 1985. p. $76-108,109-127$.

GILROY, Paul. "Identidade, Pertencimento e a Crítica da Similitude Pura". In: Entre Campos: Naçóes, Cultura e o Fascinio da Raça. Tradução de Célia Maria Marinho de Azevedo et al. Sáo Paulo: Annablume, 2007. p. 123-162.

GODDARD, Peter. Kent Monkman: Man of Mischief: Artist injects masters' style with modern themes of race and sexuality. The star. Toronto, November n. 22, 2007. Disponível no site: http://www.thestar.com/article/278281. Acessado em 15/05/2010

GONICK, Noam. Contempo Abo: Two Spirit in Aboriginal Culture. Canadian Dimension. V. 43, n. 1, July/ August, 2009: The Queer Issue. Disponível no site: http://canadiandimension.com/articles/2413/ Acessado em 16/05/2010. 
GUATTARI, Félix. "O Novo Paradigma Estético". In: Caosmose: Um Novo Paradigma Estético. Traduçáo de Ana Lúcia de Oliveira e Lúcia Cláudia Leáo. Rio de Janeiro: Editora 34, 1992. p. 127-148.

HALBERSTAM, Judith. Female Masculinity. Durham: Duke University Press, 1998.

HILL, Liz. "How Native Americans viewed Homosexuality?" In: BARROWS, Sally (ed.) Do All Indians Live In Tipis? New York: Smithsonian Institution, 2007. p. 196-197.

LATOUR, Bruno. Iconoclash: Beyond the Image Wars in Science, Religion and Art. Germany: MIT Press and ZKM Karlsrube, 2002.

Jamais Fomos Modernos : Ensaio de Antropologia Simétrica. Tradução de Carlos Irineu da Costa. Rio de Janeiro: Editora 34, [1991] 1994.

McCLINTOCK, Anne. Couro Imperial: Raça, Travestismo e o Culto da Domesticidade. Cadernos Pagu, Campinas, n. 20, 2003. p. 7-85.

MITCHELL, Timothy. Orientalism and the exhibitionary order. In: DIRKS, Nicholas (org.). Colonialism and culture. Michigan: University of Michigan Press, 1992. p. 289-317.

NMAI Editions. Do All Indians Live in Tipis? Questions and Answers from the National Museum of the American Indian. Washington D.C: Smithsonian Institution Press, 2007.

RORTY, Richard. "Acerca do Etnocentrismo: Uma Réplica a Clifford Geertz". In: Objetivismo, Relativismo e Verdade: Escritos Filosóficos V. 1. Tradução de Carlos Irineu da Costa. Rio de Janeiro: Relume Dumará, 2002. p. 271-280.

SAHLINS, Marshal. O "Pessimismo Sentimental" e a Experiência Etnográfica: Por Que a Cultura não é um "Objeto" em Via de Extinçáo (Parte II). Mana: Estudos de Antropologia Social. Rio de Janeiro: contracapa, v. 3, n. 2, 1997. p. 103-150.

. "O Que é o Iluminismo Antropológico? Algumas Liçôes do Século XX”. In: Cultura na Prática. Tra- dução de Vera Ribeiro. Rio de Janeiro: Editora UFRJ, 2004. p. 535-562.

SPIVAK, Gayatri Chakravorty. Pode o Subalterno Falar? Tradução de Sandra Regina Goulart Almeida, Marcos Pereira Feitosa e André Pereira. Belo Horizonte: Editora UFMG, 2010.

STRATHERN, Marilyn. O Gênero da Dádiva: Problemas com as Mulheres e Problemas com a Sociedade na Melanésia. Tradução de André Villalobos. Campinas: Editora da UNICAMP, [1998] 2006.

TUCHMAN, Bárbara. A Prática da História. Tradução de André Villalobos. Rio de Janeiro: José Olympio, 1991.

VIVEIROS DE CASTRO, Eduardo. O Nativo Relativo. Mana: Estudos de Antropologia Social, Rio de Janeiro: Contracapa, v. 8, n. 1, 2002a. p. 113-148.

"Perspectivismo e Multinaturalismo na América indígena”. In: A Inconstância da Alma Selvagem. São Paulo: Cosac \& Naify, 2002b. p. 345-399.

Perspectival Anthropology And the Method of Controlled Equivocation. Colóquio Americanistas, Miami, 2004. Disponível no site: http://amazone.wikia. com/wiki/Introdu\%C3\%A7\%C3\%A3o_a\%C3\%A9t odo_do_perspectivismo. Acessado em 20/05/2010

VRIES, Kylan Mattias de. "Berdache (Two-Spirited)". In: O'BRIEN, Jodi (ed.). Encyclopedia of Gender and Society V. 2. California: Sage Publications, 2009. p. 62-65.

SCHIERLE, Sonja. "Travels in the Interior of North America: The fascination and reality of Native American cultures". In: BODMER (ed.). The American Indian. Köln: Taschen GmbH, 2005. p. 8-15.

SWANSON, K. The Noble Savage Was a Drag Queen: Hybridity and Transformation in Kent Monkman's Performance and Visual Art Interventions. Hemispheric Institute's E-misférica forum. n. 22, 2005. p. 10. Disponível no Site: http://hemi.nyu.edu/journal/2_2/ pdf/swanson.pdf. Acessado em 13/05/2010.

WAGNER, Roy. A Invenção da Cultura. Tradução de Marcela Coelho de Souza e Alexandre Morales. Sáo Paulo: CosacNaify, [1981] 2010. autor Leonardo Carvalho Bertolossi

Doutorando/ FFLCH-USP

Recebido em 22/02/2011

Aceito para publicação em 26/09/2011 